\title{
SIMULASI OPTIMASI SISTEM PENCAHAYAAN LABORATORIUM SUHU DAN LABORATORIUM VOLUME
}

\author{
Fitria Hidayanti ${ }^{1}$ \\ Program Studi Teknik Fisika, Universitas Nasional ${ }^{1}$ \\ fitriahidayanti@gmail.com
}

Submitted November 29, 2019; Revised December 1, 2019; Accepted December 3,2019

\begin{abstract}
Abstrak
Laboratorium Suhu dan Laboratorium Volume Unit Pengelola Metrologi yang terletak di bawah tanah memerlukan pencahayaan buatan agar memenuhi standar pencahayaan yang berlaku. Penelitian ini bertujuan untuk mengetahui tingkat pencahayaan berdasarkan acuan SNI dengan pengukuran, analisis data dan simulasi software Calculux agar memberikan solusi demi pemenuhan Standar Nasional Indonesia (SNI). Hasil pengukuran tingkat pencahayaan laboratorium suhu 338 lux dan laboratorium volume 134 lux. Simulasi dengan software Calculux memberikan solusi pemenuhan SNI dengan mengubah posisi lampu dan angka reflektansi dinding sehingga nilai rekomendasi pencahayaan laboratorium sebesar 500 lux tercapai.
\end{abstract}

Kata Kunci : Pencahayaan, Iluminasi, Reflektansi, Calculux

\begin{abstract}
Temperature Laboratory and Volume Laboratory of Metrology Department located on basement need artificial lighting that meets applicable lighting standard. The purpose of this research is to assess the illuminating base on SNI standard using measurement, data analysis, and Calculux software simulation to get the solution of the fulfilment of SNI standard. Based on the measurement, it showed that the illuminating of temperature laboratory was 338 lux and volume laboratory was 134 lux. The solution to SNI compliance was to using Calculux software simulation and the result obtained by changing the position of the lamps and the wall reflectance rate so that a laboratory lighting recommendation value of 500 lux is reached.
\end{abstract}

Key Words : lighting, illumination, reflectance, Calculux

\section{PENDAHULUAN}

Dalam menjalankan fungsinya, Unit Pengelola Metrologi Provinsi DKI Jakarta membutuhkan ruang instalasi dan laboratorium untuk menunjang kegiatan pemeriksaan, pengujian dan kalibrasi alatalat ukur [1]. Laboratorium sebagai tempat melakukan pengujian dan kalibrasi memerlukan pencahayaan ruang yang baik. Laboratorium suhu dan laboratorium volume pada Unit Pengelola Metrologi Provinsi DKI Jakarta yang terletak di bawah tanah membutuhkan pencahayaan buatan agar tujuan peruntukan ruang laboratorium sebagai tempat kerja yang nyaman dapat terpenuhi secara maksimal.

Tujuan dari penelitian ini yaitu untuk mengukur tingkat pencahayaan yang ada pada laboratorium suhu dan laboratorium volume Unit Pengelola Metrologi. Setelah dilakukan pengukuran, dibuat simulasi sistem pencahayaan pada software computer untuk mengetahui bahwa software yang digunakan menghasilkan data yang valid. Kemudian dilakukan evaluasi tingkat pencahayaan laboratorium agar sesuai dengan rekomendasi SNI yaitu sebesar 500 lux [2] - [3].

\section{METODE PENELITIAN}

Penelitian diawali dengan mengamati kondisi pencahayaan di dalam laboratorium. Tahap selanjutnya mengukur dimensi ruangan dan mengidentifikasi jenis dan jumlah luminer yang digunakan pada laboratorium. Luas ruangan digunakan untuk menentukan titik 
pengukuran berdasarkan aturan standar ruangan. Tahap terakhir dilakukan pengukuran tingkat pencahayaan buatan masing-masing laboratorium dengan menggunakan luxmeter. Data yang didapat dari pengukuran, akan digunakan sebagai bahan untuk menganalisis pencahayaan yang ada di laboratorium sehingga dapat dibuat kondisi pemenuhan SNI dengan menggunakan software Calculux [4] - [5]. Tahapan penelitian ditunjukkan pada Gambar 1 sebagai berikut:

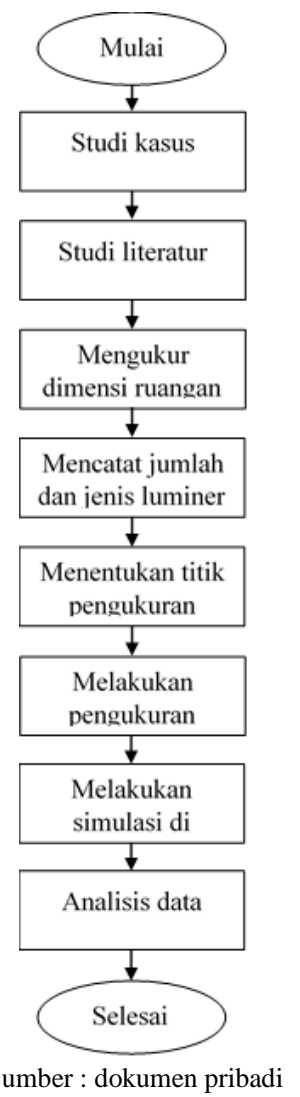

\section{Gambar 1. Diagram Alir Penelitian}

Simulasi dilakukan dengan dua skenario pencahayaan, yaitu pada kondisi verifikasi dan pada kondisi optimal. Untuk kondisi verifikasi, kondisi pencahayaan dibuat sesuai dengan hasil pengukuran di lapangan, sedangkan pada kondisi optimal, pencahayaan dibuat untuk mengetahui potensi maksimum intensitas pencahayaan yang tersebar didalam ruangan [6] - [7]. Pada kondisi ini, lampu yang digunakan untuk simulasi telah diganti agar nilai tingkat pencahayaan yang didapat mencapai standar pencahayaan minimum laboratorium yaitu sebesar 500 lux.

Gambar 2 merupakan tahapan-tahapan dalam melakukan simulai pada software Calculux. Hasil pengukuran yang telah dilakukan kemudian dimasukkan kedalam software Calculux untuk dilakukan simulasi. Parameter yang telah didapatkan yaitu dimensi ruangan, nilai reflektansi dan nilai estimasi referensi dimasukkan pada kotak dialog software Calculux untuk masing-masing laboratorium. Jumlah dan jenis lampu juga dimasukkan kedalam parameter simulasi pada software Calculux.

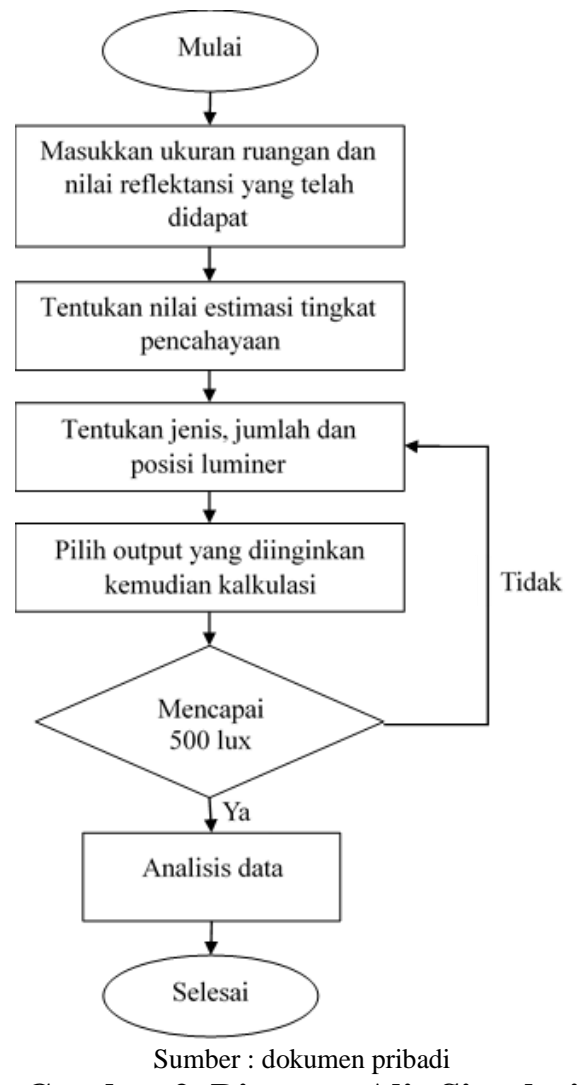

Gambar 2. Diagram Alir Simulasi

Data yang telah didapatkan pada saat pengukuran, digunakan sebagai bahan pembanding antara hasil pengukuran dengan standar rekomendasi SNI. Jika masih belum memenuhi syarat, selanjutnya dilakukan simulasi menggunakan software Calculux dengan kondisi pencahayaan optimal sehingga mendapatkan solusi pencahayaan yang tepat. Berikut data luas 
ruangan yang didapatkan dari hasil pengukuran:

\section{Tabel 1. Dimensi Ruangan Laboratorium}

\begin{tabular}{|c|c|c|c|c|}
\hline$\underline{\text { Laboratorium }}$ & $\frac{\text { Panjang }}{(\mathrm{m})}$ & $\frac{\text { Lebar }}{(\mathrm{m})}$ & $\frac{\underline{\text { Tinggi }}}{\underline{(\mathrm{m})}}$ & $\frac{\text { Luas }}{\left(\mathrm{m}^{2}\right)}$ \\
\hline Suhu & 3,87 & 2,86 & 2,90 & 11,07 \\
\hline Volume & 4,70 & 3,30 & 2,90 & 15,51 \\
\hline
\end{tabular}

Penentuan titik ukur didasarkan pada penerangan setempat dan penerangan umum. Untuk penerangan setempat dilakukan di tempat obyek kerja, baik berupa meja kerja maupun peralatan kerja. Pengukuran pada penerangan setempat dilakukan di atas meja kerja yang terdapat pada masing-masing laboratorium.

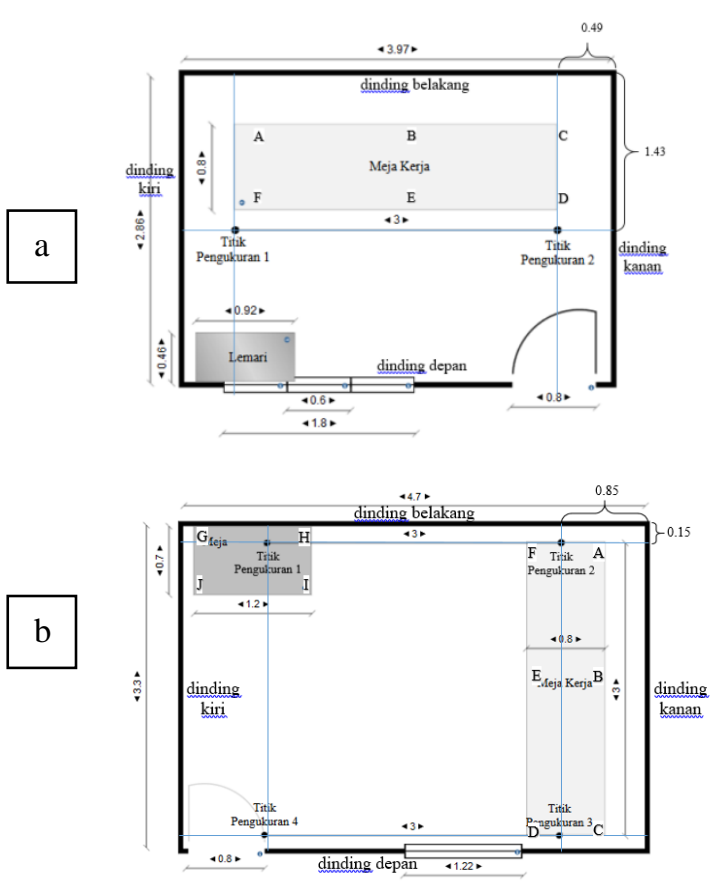

Sumber : dokumen pribadi

\section{Gambar 3. Titik Pengambilan Data Iluminasi}

(a) Laboratorium Suhu (b) Laboratorium Volume

Untuk penerangan umum dilakukan di seluruh area tempat kerja. Berdasarkan SNI 16-7062-2004 tentang pengukuran intensitas penerangan di tempat kerja, titik potong garis horizontal panjang dan lebar ruangan berdasarkan pada luas ruangan tersebut. Untuk luas ruangan 10 (sepuluh) meter persegi sampai dengan 100 (seratus) meter persegi, titik potong garis horizontal adalah pada tiap jarak 3 (tiga) meter [7].

Tabel 2. Jenis Luminer

\begin{tabular}{ccccc}
\hline $\begin{array}{c}\text { Labora- } \\
\text { tirum }\end{array}$ & $\begin{array}{c}\text { Jumlah } \\
\text { Lampu } \\
\text { tiap } \\
\text { Armatur }\end{array}$ & $\begin{array}{c}\text { Jenis } \\
\text { Lampu }\end{array}$ & $\begin{array}{c}\text { Warn } \\
\text { a } \\
\text { Lam } \\
\text { pu }\end{array}$ & $\begin{array}{c}\text { Fluks } \\
\text { Cahaya }\end{array}$ \\
\hline Suhu & 2 & Philips & Cool & 2.500 \\
& & TL528W & Day- \\
& lo65 & light & \\
& & 1SL/40 \\
Volume & 2 & Philips & Cool & 2.500 \\
& & TL-D36W & Day- & lumen \\
& & l54-765 & light \\
& & 1SL/25 & \\
\hline
\end{tabular}

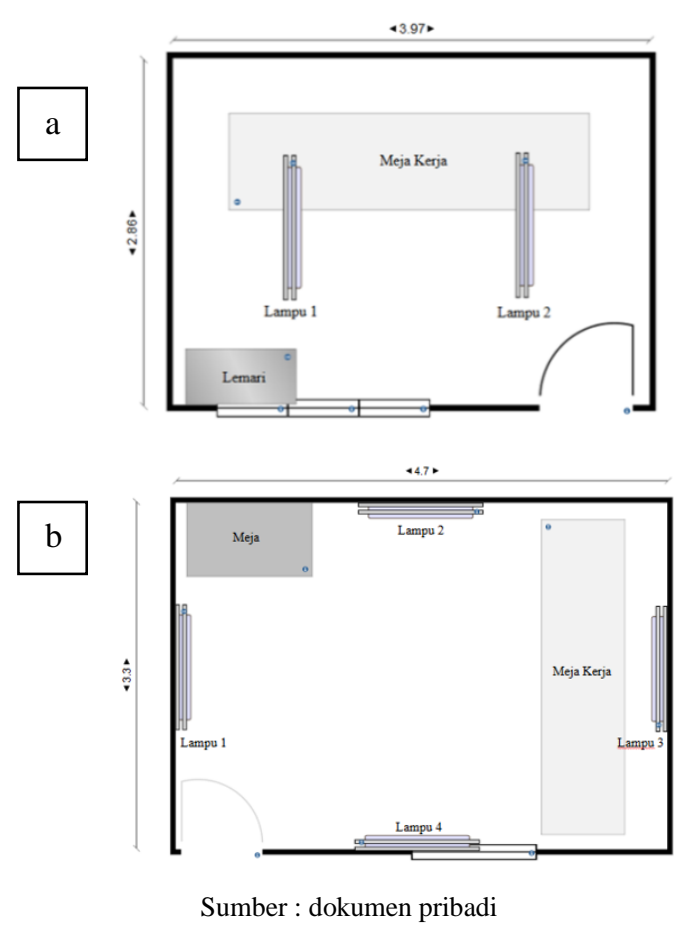

Gambar 4. Posisi Luminer

(a) laboratorium suhu, (b) laboratorium volume Jenis dan jumlah luminer digambar secara manual dengan posisi luminer pada laboratorium baik yang menyala maupun yang tidak. Hasil identifikasi jenis dan jumlah luminer ditunjukkan oleh Tabel 2 dan Gambar 4. 


\section{HASIL DAN PEMBAHASAN}

Pada laboratorum suhu diperoleh hasil sebagai berikut.

\section{a. Hasil Pengukuran Luxmeter}

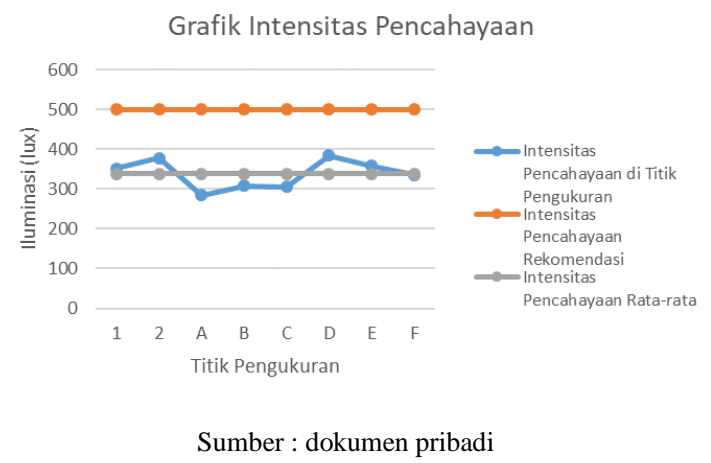

\section{Gambar 5. Hasil Pengukuran Tingkat Pencahayaan Laboratorium Suhu}

Pada Gambar 5 dinyatakan bahwa tingkat pencahayaan laboratorium suhu belum mencapai nilai yang direkomendasikan. Tingkat pencahayaan untuk ruangan laboratorium sudah merata, karena nilai pengukuran tingkat pencahayaan terendah berbanding tingkat pencahayaan rata-rata $\left(\mathrm{E}_{\text {Min }} / \mathrm{E}_{\text {Ave }}\right)$ lebih dari $80 \%$ seperti yang terlihat pada Tabel 3.

Tabel 3. Tabel Pemerataan Pencahayaan Laboratorium Suhu

\begin{tabular}{cccc}
\hline $\begin{array}{c}\text { Titik } \\
\begin{array}{c}\text { Pengukuran } \\
\text { Terendah } \\
(\text { lux })\end{array}\end{array}$ & $\begin{array}{l}\underline{\mathrm{E}}_{\text {Ave }} \\
(\mathrm{lux})\end{array}$ & $\underline{\mathrm{E}}_{\frac{\min }{(\%)}} / \underline{\mathrm{E}}_{\text {Ave }}$ & Keterangan \\
\hline 285 & 338 & 84,32 & Merata \\
\hline & & \multicolumn{2}{c}{ Sumber : dokumen pribadi }
\end{tabular}

Untuk menentukan angka reflektansi, terlebih dahulu mengambil data pengukuran sinar pantul maupun sinar langsung, Angka reflektansi ini digunakan sebagai data inputan pada simulasi Calculux.
Tabel 4. Tabel Perbandingan Reflektansi Dinding

\begin{tabular}{lll}
\hline \multirow{2}{*}{\multicolumn{1}{c}{ Bidang }} & \multicolumn{2}{c}{ Nilai Reflektansi Dinding } \\
\cline { 2 - 2 } & $\begin{array}{c}\text { Perhitungan } \\
(\%)\end{array}$ & SNI (\%) \\
\hline Dinding belakang & 66 & \\
\cline { 1 - 2 } Dinding depan & 51 & \\
\cline { 1 - 2 } Dinding kiri & 66 & \\
\hline Dinding kanan & 67 & \\
\hline Rata-rata & 62,50 & \multicolumn{2}{c}{ Sumber : dokumen pribadi }
\end{tabular}

\section{b. Simulasi Menggunakan Calculux}

1. Kondisi Eksisting

Simulasi dilakukan dilakukan dengan merancang sistem pencahayaan menggunakan lampu yang sesuai dengan yang terpasang di lapangan. Dari hasil simulasi diketahui iluminasi rata-rata hanya sebesar 336 lux, belum mencakupi 500 lux.

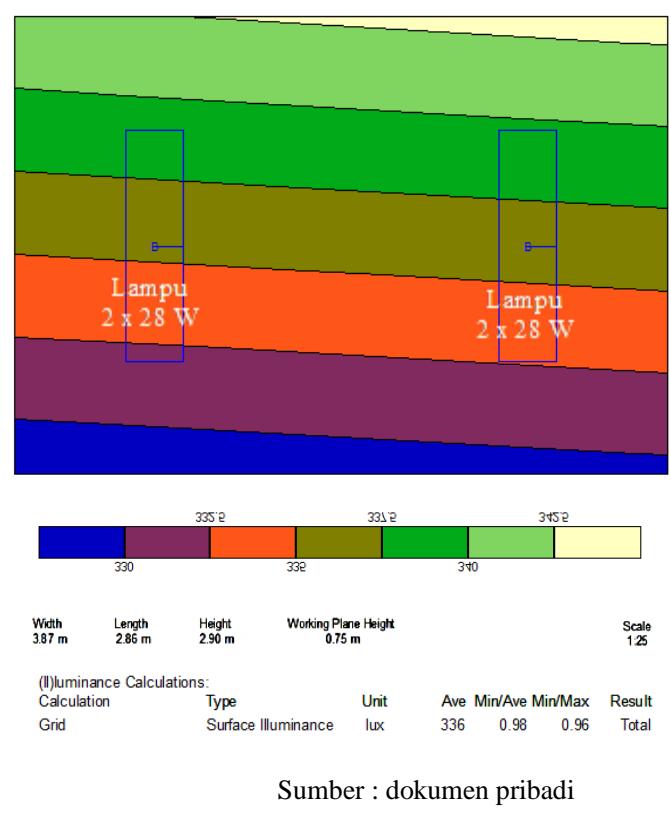

Gambar 6. Filled Iso Contour Kondisi Eksisting Laboratorium Suhu

2. Kondisi Optimal Pertama

Untuk kondisi optimal pertama, mengubah jenis lampu dengan nilai lumen yang 
dibutuhkan dan mengubah angka reflektansi menjadi sama untuk semua dinding dengan nilai yang optimal yaitu sebesar $80 \%$. Kontur cahaya yang dihasilkan sebesar 437 lux, Nilai ini belum bisa dikatakan ideal. Penyebaran cahaya juga belum merata sehingga diperlukan simulasi kedua untuk menghasilkan nilai yang sesuai.

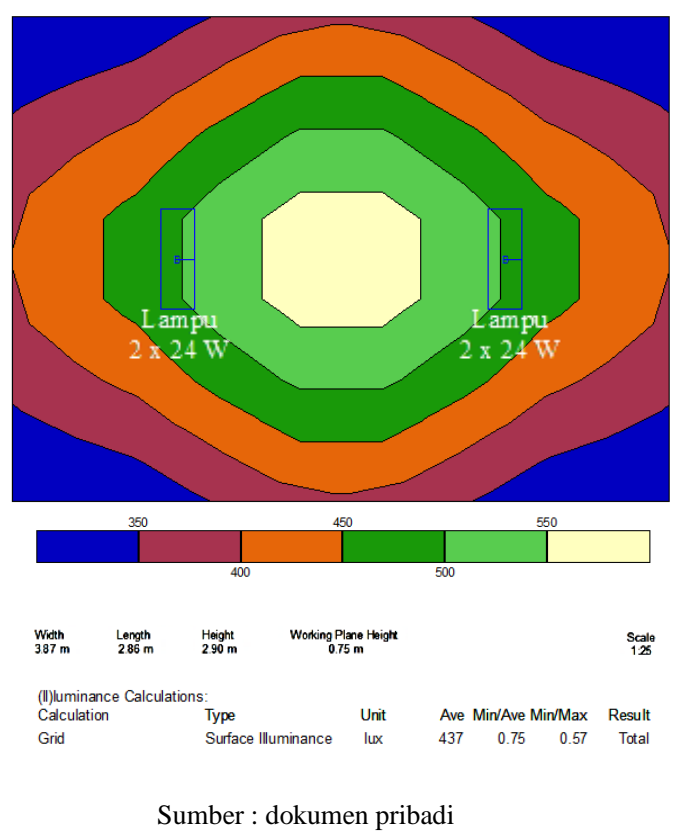

Gambar 7. Filled Iso Contour Kondisi Optimal Pertama Laboratorium Suhu

3. Kondisi Optimal Kedua

Simulasi kedua dilakukan dengan menambahkan fluks cahaya yang digunakan melebihi perhitungan pada simulasi yang pertama menjadi 2.500 lumen dengan lampu berdaya $36 \mathrm{~W}$.
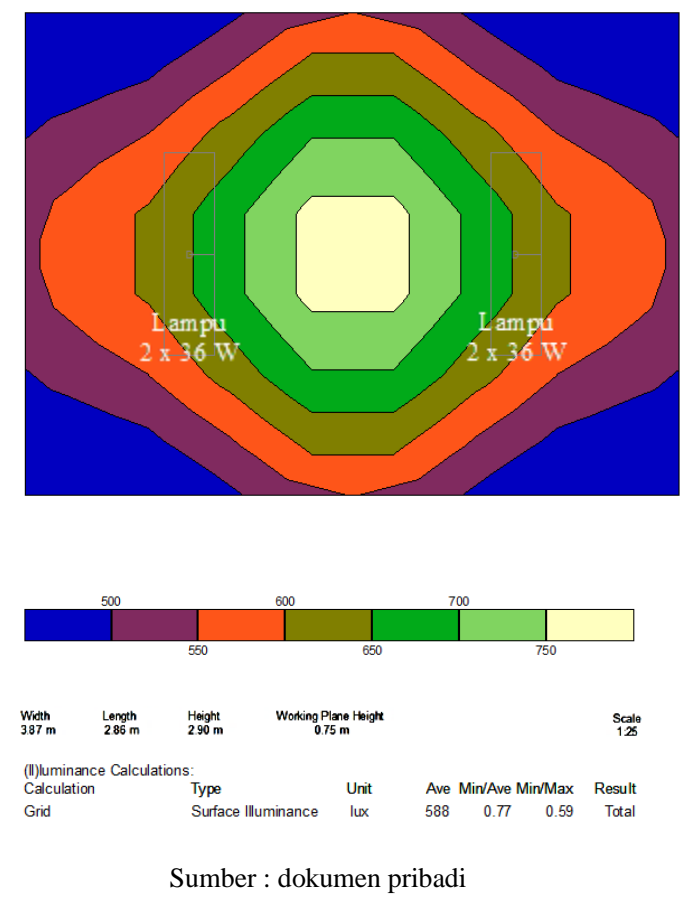

Gambar 8. Filled Iso Contour Kondisi Optimal Kedua Laboratorium Suhu

Hasil yang didapat yaitu iluminasi ratarata sebesar 588 lux, sudah mencapai kondisi ideal, akan tetapi, penyebaran cahaya belum merata karena nilai $\mathrm{E}_{\mathrm{Min}} / \mathrm{E}_{\mathrm{Ave}}$ belum mencapai angka $\geq 80 \%$ sehingga masih diperlukan simulasi lanjutan untuk menghasilkan nilai iluminasi yang sesuai.

4. Kondisi Optimal Ketiga

Simulasi ketiga masih menggunakan lampu yang sama dengan simulasi kedua, akan tetapi posisi lampu diputar $90^{\circ}$ memanjang searah panjang ruangan laboratorium. Angka reflektansi juga dibuat mencapai nilai optimal reflektansi yaitu sebesar $80 \%$. 

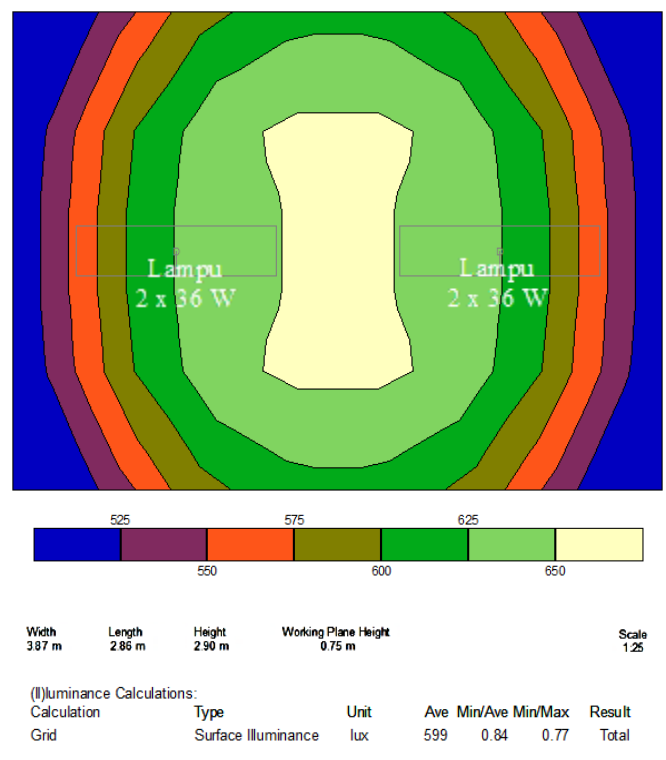

Sumber : dokumen pribadi

\section{Gambar 9. Filled Iso Contour Kondisi} Optimal Ketiga Laboratorium Suhu

Dapat dilihat pada Gambar 9, kondisi optimal yang ketiga sudah mencapai tingkat pencahayaan yang direkomendasikan. Nilai iluminasi rata-rata $\left(\mathrm{E}_{\text {Ave }}\right)$ yaitu sebesar 599 lux, dan penyebaran cahaya pada simulasi ini juga sudah merata, ditunjukkan dengan nilai $\mathrm{E}_{\text {Min }} / \mathrm{E}_{\text {Ave }}$ bernilai 0,84 atau $84 \%$.

Pada laboratorium volume, hasil yang diperoleh adalah sebagai berikut,

a. Hasil pengukuran luxmeter

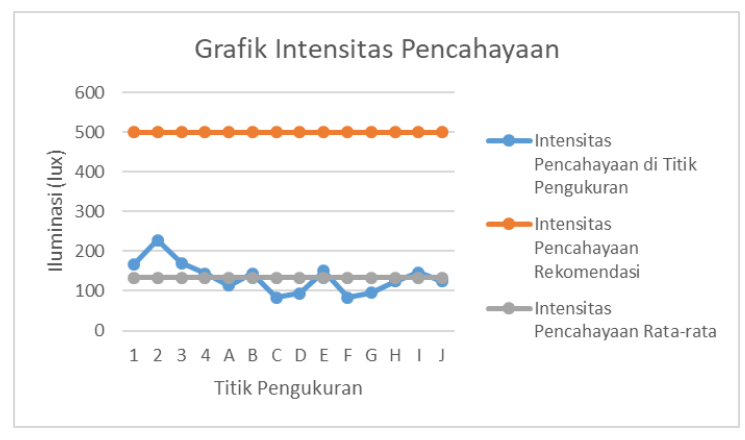

Sumber : dokumen pribadi

\section{Gambar 10. Grafik Hasil Pengukuran Tingkat Pencahayaan}

Pada Gambar 10 dinyatakan bahwa tingkat pencahayaan laboratorium volume belum mencapai nilai yang direkomendasikan. Tingkat pencahayaan untuk ruangan laboratorium juga belum merata, karena nilai pengukuran tingkat pencahayaan terendah berbanding tingkat pencahayaan rata-rata $\left(\mathrm{E}_{\mathrm{Min}} / \mathrm{E}_{\mathrm{Ave}}\right)$ kurang dari $80 \%$ seperti yang terlihat pada Tabel 5 .

\section{Tabel 5. Tabel Pemerataan Pencahayaan Laboratorium Volume}

\begin{tabular}{|c|c|c|c|}
\hline $\begin{array}{c}\text { Titik } \\
\text { Pengukuran } \\
\text { Terendah } \\
\text { (lux) }\end{array}$ & $\frac{\underline{E}_{\text {Ave }}}{(\operatorname{lux})}$ & $\frac{\mathrm{E}_{\min } / \mathrm{E}_{\mathrm{Ave}}}{(\%)}$ & Keterangan \\
\hline 83 & 134 & 61,94 & $\begin{array}{l}\text { Tidak } \\
\text { Merata }\end{array}$ \\
\hline
\end{tabular}

Untuk menentukan angka reflektansi, terlebih dahulu mengambil data pengukuran sinar pantul maupun sinar langsung, Angka reflektansi ini digunakan sebagai data inputan pada simulasi Calculux seperti yang terlihat pada Tabel 6.

\section{Tabel 6. Tabel Perbandingan Reflektansi Dinding}

\begin{tabular}{lcc}
\hline \multirow{2}{*}{ Bidang } & \multicolumn{2}{c}{ Nilai Reflektansi Dinding } \\
\cline { 2 - 2 } & Perhitungan (\%) & SNI (\%) \\
\hline Dinding belakang & 34 & \\
\hline Dinding depan & 40 & \\
\hline Dinding kiri & 63 & \\
\hline Dinding kanan & 52 & \\
\hline Rata-rata & $\mathbf{4 7 , 2 5}$ & \\
\hline \multicolumn{2}{c}{ Sumber : dokumen pribadi }
\end{tabular}

\section{b. Simulasi menggunakan Calculux \\ 1. Kondisi Eksisting}

Simulasi dilakukan dilakukan dengan merancang sistem pencahayaan menggunakan lampu yang sesuai dengan yang terpasang di lapangan. Dari hasil simulasi diketahui iluminasi rata-rata sebesar 139 lux, belum mencapai angka rekomendasi standar yaitu sebesar 500 lux. Penyebaran cahaya pada simulasi kondisi eksisting juga belum merata karena nilai $\mathrm{E}_{\mathrm{Min}} / \mathrm{E}_{\mathrm{Ave}}$ belum mencapai angka $\geq 80 \%$. 

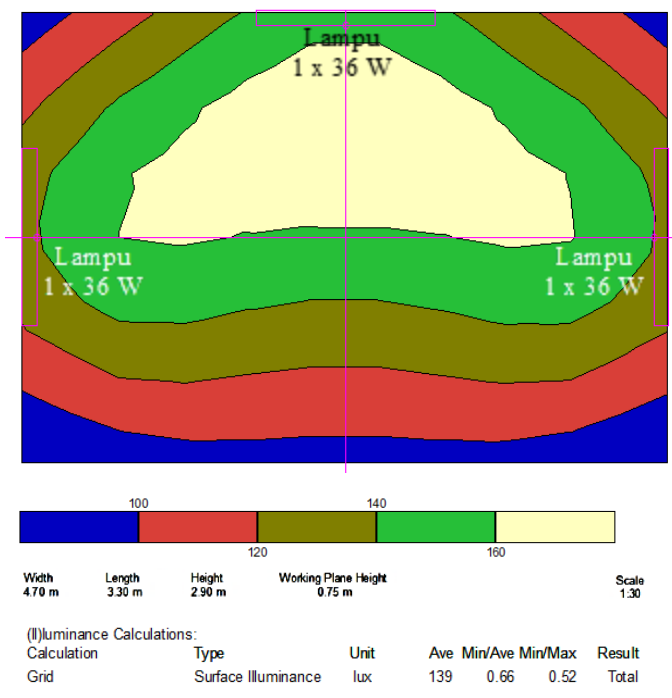

Sumber : dokumen pribadi

\section{Gambar 11. Filled Iso Contour Kondisi} Eksisting pada Laboratorium Volume

2. Kondisi Optimal Pertama

Untuk kondisi optimal pertama, mengubah jenis lampu dengan nilai lumen yang dibutuhkan dan mengubah angka reflektansi menjadi sama untuk semua dinding dengan nilai yang optimal yaitu sebesar $80 \%$.

Gambar 12 menunjukkan kontur cahaya yang dihasilkan yaitu sebesar 346 lux, Nilai ini belum mencakupi 500 lux. Penyebaran cahaya juga belum merata, sehingga diperlukan simulasi kedua untuk menghasilkan nilai yang sesuai.
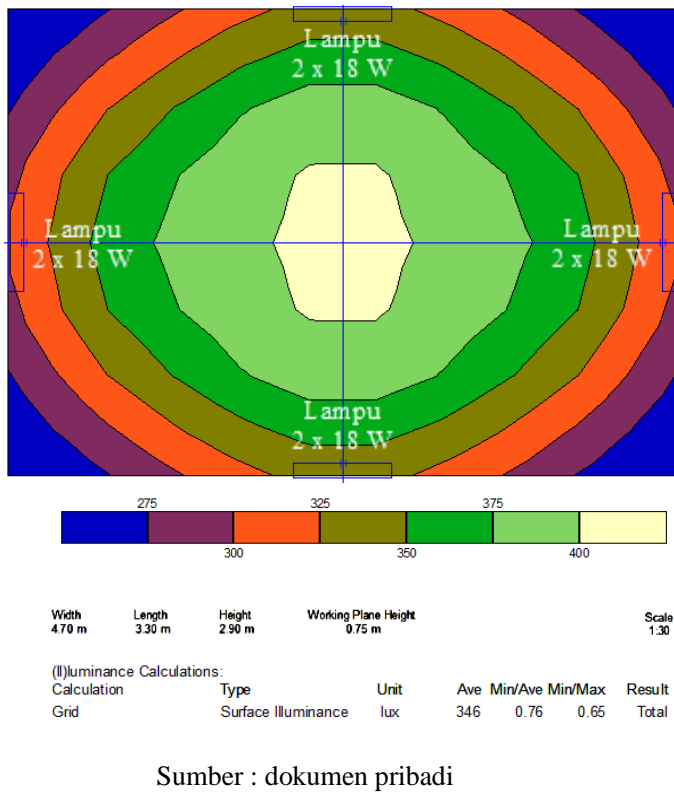

Gambar 12. Filled Iso Contour Kondisi Optimal Pertama Laboratorium Volume

3. Kondisi Optimal Kedua

Untuk kondisi optimal yang kedua, pada simulasi Calculux semua lampu yang terpasang di laboratorium difungsikan dan mengubah angka reflektansi menjadi sama untuk setiap dinding dengan nilai yang optimal yaitu sebesar $80 \%$.

Hasil simulasi pada Gambar 13 menunjukkan nilai iluminasi rata-rata $\left(\mathrm{E}_{\mathrm{Ave}}\right)$ sebesar 818 lux, sudah mencapai 500 lux, tetapi penyebaran cahaya belum merata sehingga diperlukan kondisi optimal lanjutan. 

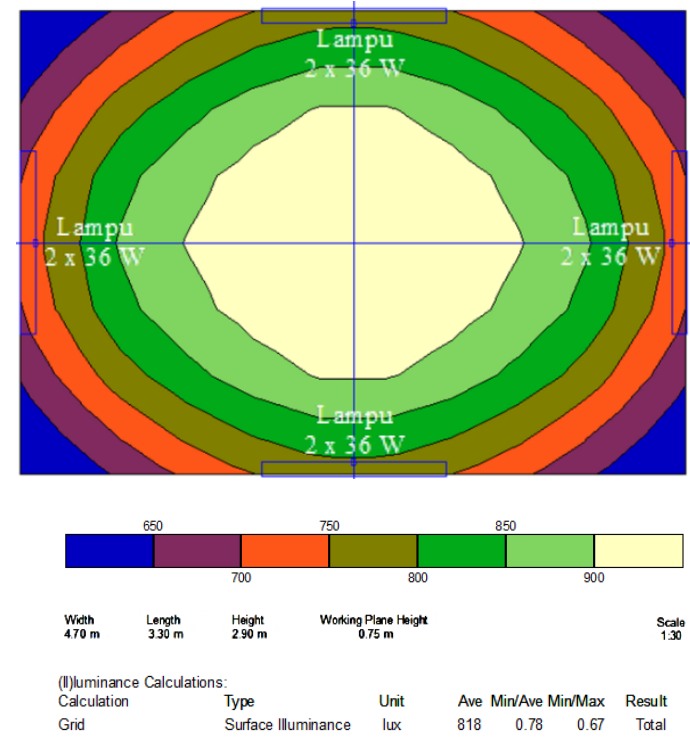

Sumber : dokumen pribadi

Gambar 13. Filled Iso Contour Kondisi Optimal Kedua Laboratorium Volume

\section{Kondisi Optimal Ketiga}

Simulasi ketiga dilakukan dengan mengurangi jumlah armatur dan mengubah letak posisi armatur menjadi di langitlangit. Angka reflektansi diubah sesuai dengan nilai optimum sebesar $80 \%$.

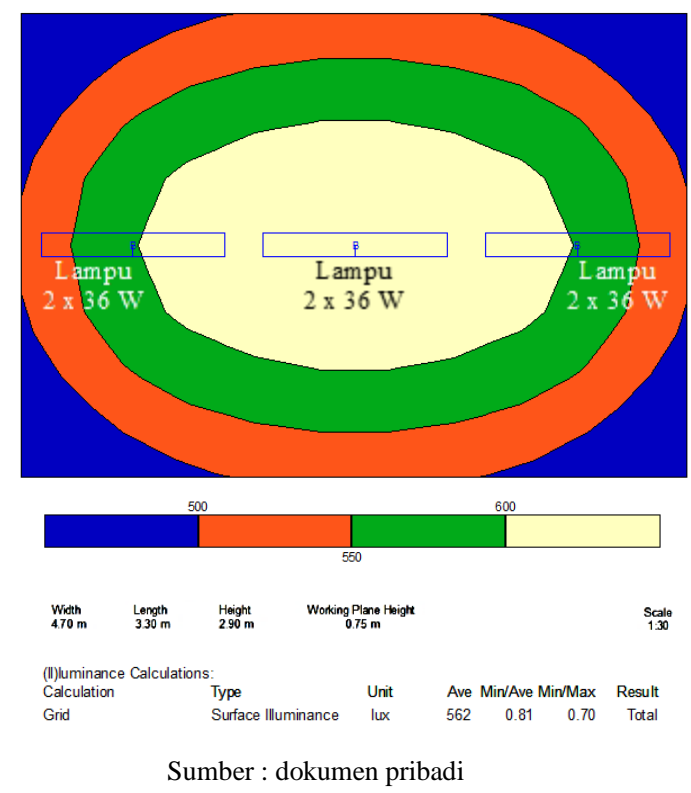

Gambar 14. Filled Iso Contour Kondisi Optimal Ketiga Laboratorium Volume
Gambar 14 menunjukkan kontur cahaya yang dihasilkan sebesar 562 lux, kondisi optimal yang ketiga sudah mencapai tingkat pencahayaan yang direkomendasikan. Penyebaran cahaya pada simulasi ini juga sudah merata, ditunjukkan dengan nilai $\mathrm{E}_{\mathrm{Min}} / \mathrm{E}_{\mathrm{Ave}}$ bernilai 0,81 atau $81 \%$.

\section{Hasil Perhitungan Nilai Error}

Tabel 7 merupakan tabel nilai error hasil dari simulasi software Calculux jika dibandingkan dengan pengukuran luxmeter.

Tabel 7. Hasil Perhitungan Nilai Error

\begin{tabular}{|c|c|c|c|}
\hline \multirow[b]{2}{*}{$\underline{\text { Laboratorium }}$} & \multicolumn{2}{|c|}{ Kondisi Eksisting } & \multirow[b]{2}{*}{$\frac{\text { Nilai }}{\underline{\text { Error }}}$} \\
\hline & $\begin{array}{c}\mathbf{E}_{\text {Ave }} \\
\text { Simulasi } \\
\text { Calculux } \\
\text { (lux) }\end{array}$ & $\begin{array}{c}\mathbf{E}_{\mathrm{Ave}} \\
\text { Pengukuran } \\
\text { Luxmeter } \\
\text { (lux) }\end{array}$ & \\
\hline$\underline{\text { Suhu }}$ & $\underline{336}$ & $\underline{338}$ & $\underline{0,59 \%}$ \\
\hline Volume & 139 & 134 & $3,73 \%$ \\
\hline
\end{tabular}

\section{SIMPULAN}

Dalam penelitian diperoleh simpulan sebagai berikut.

1. Tingkat pencahayaan rata-rata untuk laboratorium suhu sebesar 338 lux dan laboratorium volume sebesar 134 lux.

2. Pada software Calculux untuk kondisi eksisting didapat nilai pencahayaan rata-rata pada laboratorium suhu yaitu sebesar 336 lux dan laboratorium volume yaitu sebesar 139 lux. Hasil simulasi ini menghasilkan error pada software Calculux yaitu sebesar 0,59\% untuk laboratorium suhu dan $3,73 \%$ untuk laboratorium volume.

3. Optimasi pencahayaan telah dilakukan dengan mengubah beberapa kondisi untuk masing-masing laboratorium. Pada laboratorium suhu dengan mengubah posisi lampu yang terpasang dan angka reflektansi dinding sehingga didapat nilai iluminasi rata-rata sebesar 599 lux, sementara pada laboratorium volume dengan mengurangi jumlah 
armatur, mengubah angka reflektansi dinding dan letak lampu menjadi di langit-langit sehingga menghasilkan nilai iluminasi rata-rata sebesar 562 lux.

\section{UCAPAN TERIMAKASIH}

Penulis mengucapkan terima kasih kepada Program Studi Teknik Fisika, Fakultas Teknik dan Sains, Universitas Nasional, Jakarta serta Lembaga Penelitian dan Pengabdian kepada Masyarakat (LPPM) Universitas Nasional atas dukungannya.

\section{DAFTAR PUSTAKA}

[1] Pemerintah Provinsi DKI Jakarta, Peraturan Gubernur Daerah Khusus Ibukota Jakarta Nomor 309 Tahun 2016 tentang Pembentukan Organisasi dan Tata Kerja Unit Pengelola Metrologi, Jakarta: Biro Hukum Sekretariat Provinsi DKI Jakarta, 2016.

[2] Badan Standardisasi Nasional, SNI 036575-2001 tentang Tata Cara Perancangan Sistem Pencahayaan Buatan pada Bangunan Gedung, Jakarta: Badan Standardisasi Nasional, 2001.
[3] Badan Standardisasi Nasional, SNI 167062-2004 tentang Pengukuran Intensitas Penerangan di Tempat Kerja. Jakarta: Badan Standardisasi Nasional, 2004.

[4] Mostafavi A. "Optimizing the Lighting Production through Photovoltaic and Fluorescent Lamps in Iran Residential Applications by Calculux Software", J. Appl. Environ. Biol. Sci. 5(12S):472-88, 2015.

[5] Kotulski L, De Landtsheer J, Penninck S, Sędziwy A, Wojnicki I, "Supporting Energy Efficiency Optimization in Lighting Design Process". In Proc. of 12th European Lighting Conference Lux Europa, Krakow, 2013.

[6] Das A, Paul SK. "Artificial Illumination during Daytime in Residential buildings: Factors, Energy Implications and Future Predictions", Applied Energy 158:65-85, 2015.

[7] Soori, P.K. and Vishwas, M.,. "Lighting Control Strategy for Energy Efficient Office Lighting System Design", Energy and Buildings, 66, pp.329-337, 2013. 